\title{
Anticorrosion Protection by Amine-Ionic Liquid Mixtures: Experiments and Simulations
}

\author{
F. L. Bernard, ${ }^{\dagger, \dagger}$ F. Dalla Vecchia, ${ }^{\S}$ M. F. Rojas, ${ }^{\dagger}$ R. Ligabue, ${ }^{\dagger \dagger}$ M. O. Vieira, ${ }^{\dagger}$ E. M. Costa, ${ }^{\dagger, \S}$ \\ Vitaly V. Chaban, ${ }^{*, \| l}$ and S. Einloft ${ }^{\dagger,+}$
}

${ }^{\dagger}$ Post-Graduation Program in Materials Engineering and Technology, ${ }^{\ddagger}$ School of Chemistry, ${ }^{\S}$ School of Engineering, Pontifical Catholic University of Rio Grande do Sul - PUCRS, Av. Ipiranga, 6681, Partenon, Porto Alegre, CEP 90619-900, Brazil

"Federal University of São Paulo, São Paulo, SP 04021-001, Brazil

Supporting Information

ABSTRACT: The mixtures of aqueous amines and ionic liquids (ILs) are considered as potential solvents for $\mathrm{CO}_{2}$ capture. We report corrosion and $\mathrm{CO}_{2}$ absorption behavior of the mixed IL-amine solutions. The absorption tests were performed at $318.15 \mathrm{~K}$ under $0.1-2.7 \mathrm{MPa}$. The corrosion tests were carried out at $318.15 \mathrm{~K}$ under $2.7 \mathrm{MPa}$. Addition of $[\mathrm{bmim}]\left[\mathrm{BF}_{4}\right]$ in aqueous alkanolamine solutions reduces corrosion rate for MEA by up to $72 \%$. The $\mathrm{CO}_{2}$ absorption capacity in the mixtures falls between those of aqueous MDEA and pure IL. These results allow to choose the working pressure range as a function of other parameters, such as gas pressure and mixture viscosity. According to the simulations, [bmim $]\left[\mathrm{BF}_{4}\right]$ participates in the gas capture through $\mathrm{H}$-bonding, although the number of amine molecules is enough to capture all supplied $\mathrm{CO}_{2}$ molecules. The equilibrium of the chemisorption reaction is, therefore, modified upon the stepwise IL addition. An ideal IL content for preventing corrosion is $10 \% \mathrm{w} / \mathrm{w}$.

\section{INTRODUCTION}

Among carbon dioxide $\left(\mathrm{CO}_{2}\right)$ capture techniques, a chemical absorption process has been extensively studied in academe and used in industry for decades. ${ }^{1-3}$ The process uses aqueous alkanolamines solutions, such as monoethanolamine (MEA), diethanolamine (DEA), N-methyldiethanolamine (MDEA), and other amines less frequently. The chemical adsorption has a number of disadvantages, the most serious of which are the high regeneration energy penalty, ${ }^{1,4-6}$ degradation/ evaporation of amines, and equipment corrosion. ${ }^{1,4,7}$ Corrosion of low-carbon steels, commonly used as raw materials in the $\mathrm{CO}_{2}$ capture setups, constitutes a significant engineering problem. ${ }^{4,8}$ New types of physical solvents are under urgent development to decrease energy requirements for $\mathrm{CO}_{2}$ release. In this context, ionic liquids (ILs), which are liquid salts at room temperature, are interesting compounds. ILs exhibit useful properties, such as negligible vapor pressure, nonflammability, high thermal stability, and tunability. According to the recent advances, certain ILs are potential solvents for an acidic gases capture, such as $\mathrm{CO}_{2} \cdot 1,4,5,7,9-15$ Some disadvantages of pure ILs, in relation to the $\mathrm{CO}_{2}$ capture, include a relatively low $\mathrm{CO}_{2}$ sorption capacity, poor selectivity in relation to hydrocarbons (being a problem mainly in natural gas processing), necessity of high circulation rates, and high viscosity. Besides, ILs do not currently appear economically competitive, due to a high cost of their synthesis. ${ }^{16,17}$ ILs and amines exhibit excellent miscibility. Hence, the resulting systems combine beneficial properties of ILs with gas absorption capacity of aqueous alkanolamine. ${ }^{18,19}$ Ternary mixtures water-ionic liquid-amine facilitate application of ILs in the gas capture plants by (1) allowing the largest $\mathrm{CO}_{2}$ cyclic capacities; (2) reducing an average enthalpy of $\mathrm{CO}_{2}$ dissolution; ${ }^{20}$ (3) reducing energy consumption for absorbent regeneration; $^{18}$ (4) decreasing viscosity of the mixture. ${ }^{18,19}$ Process simulations were conducted to assess performance of new working systems for industry. Simulation studies reporting mixed IL-amine solutions are scarce due to complexity of this system. ${ }^{21}$ Furthermore, the solubility of $\mathrm{CO}_{2}$ in these mixtures and carbon steel corrosiveness data at high pressures are insufficient. Most available data correspond to the atmospheric pressure. $7,16,22-25$

In the present work, we report the following data, which are deemed important for the progress of the field: (1) $\mathrm{CO}_{2}$ induced corrosion of the low carbon steel; (2) $\mathrm{CO}_{2}$ absorption capacity of alkanolamines and aqueous IL solutions; (3) atomistic thermodynamics and molecular dynamics simulations. The measurements were conducted at typical temperatures and pressures of the precombustion $\mathrm{CO}_{2}$ absorption process (318.15 $\mathrm{K}$ and 2.7 MPa). We selected 1-butyl-3-methylimida-

Received: November 23, 2015

Accepted: March 15, 2016

Published: March 22, 2016 
zolium tetrafluoroborate, $[\mathrm{bmim}]\left[\mathrm{BF}_{4}\right]$ as an $\mathrm{IL}$ for investigation, due to its ability to form hydrogen bonds with $\mathrm{CO}_{2}$.

\section{EXPERIMENTAL SECTION}

2.1. Preparation of Test Solutions and Steel Specimens. The $[\mathrm{bmim}]\left[\mathrm{BF}_{4}\right]$ IL was in-home synthesized, according to literature. ${ }^{26,27}$ The structure was confirmed by (1) infrared spectroscopy Fourier transform (FTIR) using PerkinElmer spectrophotometer model Spectrum 100 FT-IR with full attenuated reflectance mode (ATR) in transmittance and (2) proton nuclear magnetic resonance $\left({ }^{1} \mathrm{H} \mathrm{NMR}\right)$ in Varian spectrophotometer, model-VNMRS $300 \mathrm{MHz}$, using (DMSO- $d_{6}$ ) as solvent and glass tubes of diameter $5 \mathrm{~mm} .{ }^{1} \mathrm{H}$ NMR $\left(300 \mathrm{MHz}\right.$, DMSO- $\left.d_{6}, 25^{\circ} \mathrm{C}\right) \delta(\mathrm{ppm}): 1.01\left(\mathrm{~m}, \mathrm{CH}_{3}\right)$, $1.29\left(\mathrm{~m}, \mathrm{CH}_{2} \mathrm{CH}_{3}\right), 1.83\left(\mathrm{~m}, \mathrm{CH}_{2}\right), 3.97\left(\mathrm{~s}, \mathrm{CH}_{3}\right), 4.25(\mathrm{t}$, $\left.\mathrm{CH}_{2} \mathrm{~N}\right), 7.79\left(\mathrm{~s}, \mathrm{H}_{5}\right), 7.91\left(\mathrm{~s}, \mathrm{H}_{4}\right), 9.48\left(\mathrm{~s}, \mathrm{H}_{2}\right)$. FTIR $\left(\mathrm{cm}^{-1}\right)$ : $3151(\mathrm{~N}-\mathrm{H}$, imidazole ring), $3120(\mathrm{C}-\mathrm{H}$, imidazole ring), $2963\left(\mathrm{C}-\mathrm{H}\right.$ of $\left.\mathrm{CH}_{2}\right), 2878\left(\mathrm{C}-\mathrm{H}\right.$ of $\left.\mathrm{CH}_{3}\right), 1620(\mathrm{C}=\mathrm{N}$, imidazole ring), 1572 and $1457(\mathrm{C}=\mathrm{C}$ and $\mathrm{C}-\mathrm{N}$, imidazole ring), 1015 and 845 (B-F). MEA, MDEA, $\mathrm{CO}_{2}$ (air liquid/ $99.998 \%$ ), and $\mathrm{N}_{2}$ (air products $\geq 99.999 \%$ ) were used without further purification.

The test solutions used in the experiments were composed by deionized water, $[\mathrm{bmim}]\left[\mathrm{BF}_{4}\right]$, aqueous alkanolamines solution $(50 \% \mathrm{w} / \mathrm{w})$, and mixtures of aqueous alkanolamine solution $(50 \% \mathrm{w} / \mathrm{w})$ with $[\mathrm{bmim}]\left[\mathrm{BF}_{4}\right](10 \%$ to $50 \% \mathrm{w} / \mathrm{w})$, Table 1.

Table 1. Test Solutions Used in the $\mathrm{CO}_{2}$ Capture Experiments

\begin{tabular}{lll}
\hline \multicolumn{1}{c}{ test solution } & IL concentration $(\% \mathrm{w} / \mathrm{w})$ & acronym \\
\hline$[\mathrm{bmim}]\left[\mathrm{BF}_{4}\right]$ & 100 & $\mathrm{IL}$ \\
$\mathrm{MEA}$ & 0 & $\mathrm{M} 0$ \\
$\mathrm{MEA}+[\mathrm{bmim}]\left[\mathrm{BF}_{4}\right]$ & 10 & MIL10 \\
$\mathrm{MEA}+[\mathrm{bmim}]\left[\mathrm{BF}_{4}\right]$ & 25 & MIL25 \\
$\mathrm{MEA}+[\mathrm{bmim}]\left[\mathrm{BF}_{4}\right]$ & 35 & MIL35 \\
$\mathrm{MEA}+[\mathrm{bmim}]\left[\mathrm{BF}_{4}\right]$ & 50 & MIL50 \\
$\mathrm{MDEA}$ & 0 & MD0 \\
$\mathrm{MDEA}+[\mathrm{bmim}]\left[\mathrm{BF}_{4}\right]$ & 10 & MDIL10 \\
$\mathrm{MDEA}+[\mathrm{bmim}]\left[\mathrm{BF}_{4}\right]$ & 25 & MDIL25 \\
$\mathrm{MDEA}+[\mathrm{bmim}]\left[\mathrm{BF}_{4}\right]$ & 35 & MDIL35 \\
$\mathrm{MDEA}+[\mathrm{bmim}]\left[\mathrm{BF}_{4}\right]$ & 50 & MDIL50 \\
\hline
\end{tabular}

Low carbon steel has the following chemical composition: $n(\mathrm{C})=0.10 \%, n(\mathrm{Mn})=0.51 \%, n(\mathrm{Si})=0.05, n(\mathrm{P})=0.001 \%$, $n(\mathrm{~S})=0.005 \%, n(\mathrm{Fe})=$ balance. Specimens $10 \mathrm{~mm} \times 10 \mathrm{~mm} \times$ $10 \mathrm{~mm}$ were used in all high-pressure corrosion experiments. Prior to experiments, the specimens were polished using the silicon carbide paper $(320,400,600$, and 1200 grit), cleaned in distilled water, degreased in acetone, and dried in hot air.

2.2. Corrosion Tests. Corrosion tests were performed in autoclave at static conditions, during $168 \mathrm{~h}$. This time is longer than an average time of the corrosion experiments, reported in literature. The specimens were placed into the container inside the autoclave of $0.120 \mathrm{~L}$ and immersed in $0.050 \mathrm{~L}$ of the test solution. The autoclave was sealed; the system was purged with nitrogen to deoxygenate the solution test during $1 \mathrm{~h}$ and purged by $\mathrm{CO}_{2}$ during $1 \mathrm{~h}$. Then, the autoclave was pressurized with $\mathrm{CO}_{2}$ up to pressure $2.7 \mathrm{MPa}$ and heated up to $318.15 \mathrm{~K}$. The employed experimental setup is exemplified in Figure S1.

2.3. Post-Corrosion Examination. After the corrosion tests, the carbon steel specimens were cleaned in distilled water and dried in cold air. Scanning electron microscope (SEM) (Carls Zeiss model EVO LS15) equipped with energy dispersive spectrometer (EDS) was used to analyze chemical composition, morphology, and characteristics of the scales formed on the surfaces of the steel specimens. For this purpose, the samples were covered with a thin layer of gold. Scale properties were also evaluated by the potentiodynamic polarization technique. Electrochemical experiments were carried out at atmospheric pressure and ambient temperature using the Autolab $302 \mathrm{~N}$ equipment. A conventional threeelectrode cell with a working volume of $0.05 \mathrm{~L}$ was used, equipped with a saturated calomel electrode (SCE), as the reference electrode, and the platinum electrode as counter electrode. All electrochemical measurements were conducted after the electrodes were immersed in aerated solution of $\mathrm{Na}_{2} \mathrm{SO}_{4}-0.1 \mathrm{M}(\mathrm{pH} 7.00)$ for $1 \mathrm{~h}$ to determine the open circuit potential (OCP). The potentiodynamic measurements were performed in the potential range from $-200 \mathrm{mV}$ below the open circuit potential to $300 \mathrm{mV}$ with a scan rate of $1 \mathrm{mV}$ / s. $^{28,29}$

An average corrosion rate of steel was determined according to the mass loss technique, in which the removal of corrosion products from the corrosion test specimens was carried out in accordance with ASTM G1-03 (2011), ${ }^{30}$ by immersing the carbon steel specimens in 1:1 mixture of water and hydrochloric acid $(\mathrm{HCl})$ and $3.5 \mathrm{~g}$ of hexamethylene tetramine. A number of cleaning cycles was recorded. The weight loss monitored until its changes were observed. In accordance with ASTM G1-03 (2011) $)^{30}$ and ASTM G31-72 (2004), ${ }^{31}$ the corrosion rate $(\mathrm{CR})$ in millimeter per year $(\mathrm{mm} / \mathrm{y})$ was obtained by the following equation:

$$
\mathrm{CR}=\frac{K W}{A t d}
$$

where $K$ is constant $\left(8.76 \times 10^{4}\right), t$ is the time of exposure (hours), $A$ is the area $\left(\mathrm{cm}^{2}\right), W$ is the mass loss $(\mathrm{g})$, and $d$ is the density $\left(\mathrm{g} / \mathrm{cm}^{3}\right)$.

2.4. Carbon Dioxide Absorption Measurements. The absorption of $\mathrm{CO}_{2}$ in the test solutions was gravimetrically assessed in the magnetic suspension balance (MSB) (Rubotherm Prazisionsmesstechnik $\mathrm{GmbH}, 35 \mathrm{MPa}$ and $673.15 \mathrm{~K})$, equipped with a single sinker device for the adsorbate density determination and thermostatized with an oil bath (Julabo F25/ $\pm 273.16 \mathrm{~K}$ ). The apparatus is described in detail elsewhere. $^{32,33}$ When compared to other gravimetrical sorption methods, the MSB device allows high pressure sorption measurements, since the sample can be potted into closed chamber coupled to an external precise balance (the accuracy is $\pm 10 \mu \mathrm{g})$. The test solutions $(0.06-0.09 \mathrm{~g})$ were weighted and transferred to the MSB sample container. The system was subjected to the $10^{-7} \mathrm{MPa}$ vacuum at $318.15 \mathrm{~K}$, for $0.08 \mathrm{~h}$. For the IL sample, the vacuum time was $24 \mathrm{~h}$ to achieve constant weight. The $\mathrm{CO}_{2}$ (air liquid/99.998\%) was admitted into the MSB pressure chamber up to the desired pressure, 0.1-2.7 MPa. The pressure gauge with an accuracy of $10^{-3}$ $\mathrm{MPa}$ was used to control system pressure. The solubility of $\mathrm{CO}_{2}$ in the test solutions was measured 3-4 h after no more weight increase of the solution was observed. At this step of the $\mathrm{CO}_{2}$ solubility in the test solutions, the weight obtained from the microbalance at pressure $P$ and temperature $T$ is recorded as $W_{\mathrm{t}}(P, T)$. The mass of dissolved $\mathrm{CO}_{2}$ in the test solutions $\left(W_{\mathrm{g}}\right)$ was calculated using the following equation, 


$$
\begin{aligned}
W_{\mathrm{g}}= & {\left[W_{\mathrm{t}}(P, T)-W_{\mathrm{sc}}(P, T)+\rho(P, T) .\right.} \\
& \left.\left(V_{\mathrm{sc}}(T)+V_{\mathrm{ts}}(T)\right)\right]-W_{\mathrm{ts}}(\mathrm{vac}, T)
\end{aligned}
$$

where $W_{\mathrm{sc}}(P, T)$ is the weight of the sample container; $\rho(P, T)$ is the $\mathrm{CO}_{2}$ density, directly measured with the MSB coupled single-sinker device; $V_{\mathrm{sc}}(T)$ is the volume of the sample container, determined from a buoyancy experiment when no sample is charged into the sample container; $V_{\mathrm{ts}}(T)$ is an original volume of the test solution; $W_{\mathrm{ts}}(\mathrm{vac}, T)$ is weight of the test solution under vacuum. $\rho(P, T) \cdot\left(V_{\mathrm{sc}}(T)+V_{\mathrm{ts}}(T)\right)$ represents the buoyancy force.

2.5. Thermodynamic Electronic-Structure Numerical Simulations. Thermodynamic potentials (enthalpy, entropy, Gibbs free energy) were computed using molecular partition functions, as exemplified in ref 34. The wave function optimization followed by geometry optimization was supplemented by computation of force constants and corresponding vibrational frequencies. The coupled-cluster theory with triple excitations ${ }^{35}$ was used in this work as an electron-correlation post-Hartree-Fock method. The split-valence triple- $\zeta 6-311+$ $+\mathrm{G}^{* *}$ basis set was applied to all atoms, irrespective of their identity. The wave function energy convergence criterion at every self-consistent field step was set to $10^{-8}$ hartree. Figure 1 depicts optimized geometries of the selected considered systems for thermodynamic calculations. Preferential molecular orientations can be observed.

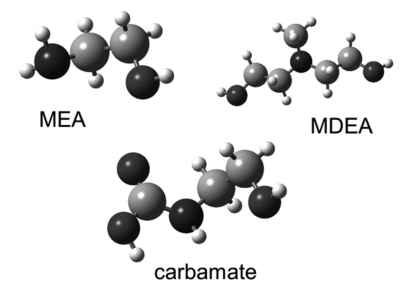

Figure 1. Investigated molecules: (a) MEA; (b) MDEA; (c) carbamate obtained by chemisorption of MEA. The depicted geometries were thoroughly optimized following evolution of energy gradients. Carbon atoms are gray, hydrogen atoms are white, nitrogen atoms are black, and oxygen atoms are dark gray.

The thermodynamic potentials of each process were computed from ab initio data based on the Hess's law of constant heat summation and widely known thermodynamic relations among enthalpy, entropy, and Gibbs free energy. The gas-phase behavior was assumed.

2.6. Molecular Dynamics Simulations. Molecular dynamics (MD) simulations provide a powerful tool to investigate materials with an atomistic resolution. PM7-MD simulations $^{36-40}$ were performed in this work to characterize complex systems consisting of amines, water, ionic liquid, and carbon dioxide (Table 2). The PM7-MD method was successfully applied to versatile problems in molecular physics including gas capture, ${ }^{39}$ competitive solvation, ${ }^{38}$ ion-molecular systems, ${ }^{37}$ metal structures, ${ }^{36}$ and so forth. PM7-MD uses the PM7 Hamiltonian ${ }^{40}$ to obtain immediate forces on every atom at every integration time step. These forces are used to propagate equations-of-motion, thus bringing the systems to thermodynamic equilibria and sampling their phase spaces afterward. Note that the PM7-MD method does not use force field models of any kind. The method operates with individual valence electrons. Therefore, all quantum effects, such as
Table 2. List of Systems Simulated Using PM7-MD, Their Compositions, and the Corresponding Sampling Times ${ }^{a}$

$\begin{array}{clccccc}\text { no. } & \text { system name } & \begin{array}{c}\text { no. amine } \\ \text { molecules }\end{array} & \begin{array}{c}\text { no. water } \\ \text { molecules }\end{array} & \begin{array}{c}\text { no. IL } \\ \text { ion }\end{array} & \begin{array}{c}\text { no. } \\ \text { atoms }\end{array} & \begin{array}{c}\text { sampling } \\ \text { time, ps }\end{array} \\ 1 & \text { MEA } & 8 & 26 & 0 & 181 & 250 \\ 2 & \text { MEA + 1 IL } & 8 & 26 & 1 & 211 & 350 \\ 3 & \text { MEA + 2 IL } & 8 & 26 & 2 & 241 & 380 \\ 4 & \text { MEA + 3 IL } & 8 & 26 & 3 & 271 & 400 \\ 5 & \text { MDEA } & 4 & 54 & 0 & 261 & 300 \\ 6 & \text { MDEA + 1 IL } & 4 & 54 & 1 & 291 & 350 \\ 7 & \text { MDEA + 2 IL } & 4 & 54 & 2 & 321 & 480 \\ 8 & \text { MDEA + 3 IL } & 4 & 54 & 3 & 351 & 400\end{array}$

${ }^{a_{T}}$ The system compositions were selected in view of compositions of the experimentally investigated mixtures. Each simulated system contains $5 \mathrm{CO}_{2}$ molecules.

chemical bonding, electronic polarization, tunneling, and so forth are explicitly accounted for. A more detailed description of the method, including numerical validations and comparisons to more computationally expensive methods, is available in the above referenced works and particularly in the last Stewart's method-development work. ${ }^{40}$

All simulations were performed at $300 \mathrm{~K}$, which was maintained using the Andersen thermostat. ${ }^{41}$ The equationsof-motion of each atom were propagated according to the Verlet algorithm with a time-step of $0.5 \mathrm{fs}$. The relatively small time-step is necessary due to highly mobile $\mathrm{CO}_{2}$ molecules, which are only partially in the form of carbonic acid, $\mathrm{H}_{2} \mathrm{CO}_{3} \leftrightarrow$ $\mathrm{H}_{2} \mathrm{O}+\mathrm{CO}_{2}$. All atoms were allowed to move spontaneously in accordance with the Newton's second law and the Maxwell distribution of molecular kinetic energies at $300 \mathrm{~K}$.

Pair correlation functions (PCFs) show most probable distances between two given atoms. With this universal definition, PCFs can be computed both for covalently bound atoms, H-bonded atoms, and arbitrary distant atoms. The formation of intermolecular hydrogen bonds was identified using the following well-established criterion: the length of bond is smaller than $2.5 \AA$, and donor-hydrogen-acceptor angle is greater than $90^{\circ}$.

The MD simulated products were compared to the known structures of carbamates; the physical adsorption of $\mathrm{CO}_{2}$ by the imidazole ring of the [bmim] cation is well-known; the systems with better performance according to the experiment exhibit a better performance in the simulations, too.

\section{RESULTS AND DISCUSSION}

3.1. Corrosion Process versus $[\mathrm{bmim}]\left[\mathrm{BF}_{4}\right]$ Concentration. Precombustion technology works with higher $\mathrm{CO}_{2}$ contents and pressures allowing the use of physical solvents, chemical solvents, or mixtures of them. ${ }^{1}$ Accordingly, the corrosion tests were performed at $318.15 \mathrm{~K}$ and $2.7 \mathrm{MPa}$. These conditions are typical for the precombustion gas capture process. Figure 2 shows an effect of the IL concentration on the corrosion rates of carbon steel specimens determined by the weight loss technique.

In the case of the MEA solution (M0), the corrosion rate decreases considerably with the increase of the IL concentration up to $10 \%$ (MIL10). At higher concentrations, the corrosion rate of the steel specimen decays insignificantly. We suppose this behavior to occur due to formation of an ultrathin IL film on the steel specimen surface. According to previous investigations, such film blocks reaction sites, therefore, 


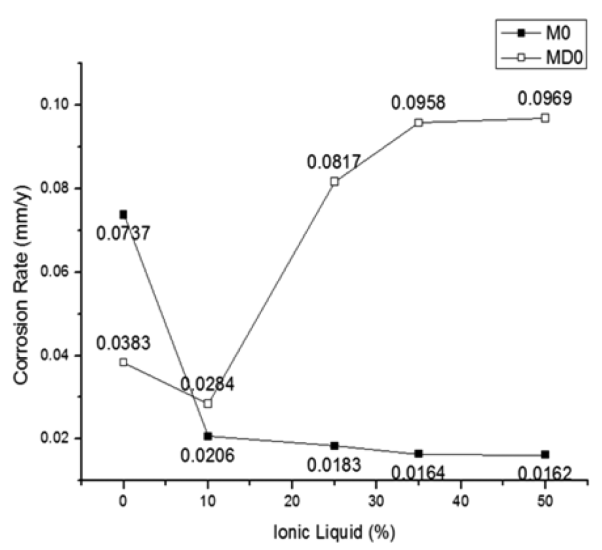

Figure 2. Corrosion rate of the carbon steel versus concentration of IL in $\mathrm{MD0}$ and $\mathrm{M} 0$. The mixtures were saturated with $\mathrm{CO}_{2}$ after $168 \mathrm{~h}$ exposure at $2.7 \mathrm{MPa}$ and $318.15 \mathrm{~K}$.

defending steel from the approaching oxidizing agents and reducing corrosion rate (Figure 2).,42 The posed supposition is supported by our electrochemical and corrosion tests. Kittel and co-workers ${ }^{3}$ reported that degradation products of MEA increase corrosion rate due to $\mathrm{pH}$ reduction. This conclusion was derived from conductivity increase and by formation of iron complexes. Therefore, reduction of carbamate formation upon IL addition decreases steel corrosion. Furthermore, addition of ILs into aqueous alkanolamines solutions increases the mixture viscosity. A higher viscosity implies reduced selfdiffusion of oxidants, which is directly related to the corrosion rate. $^{23}$

Interestingly, the MEA- $[\mathrm{bmim}]\left[\mathrm{BF}_{4}\right]$ mixtures exhibit a qualitatively different trend than that exhibited by the $[\mathrm{bmim}]\left[\mathrm{BF}_{4}\right]$ mixtures. The following explanation is proposed in this work. Viscosity of pure MEA is low. ${ }^{16,17}$ Despite chemisorption, the observed corrosion rate is significant. Even strong chemisorption (e.g., using MEA) is not enough to slow down corrosion. All molecules in the mixture move fast in the low-viscous medium. No protective film is available at the materials surface to prevent corrosion. Addition of IL increases viscosity being helpful in preventing corrosion, even though the $\mathrm{CO}_{2}$ capturing ability decreases per unit of mass/volume of the mixture. In the case of MDEA, the corrosion rate is slower than that in MEA. This is true despite the $\mathrm{CO}_{2}$ capture ability of MDEA is inferior to that of MEA. Viscosity plays an important role, since MDEA is more viscous than MEA (larger molecules result in higher viscosities). Addition of viscous IL increases viscosity of the mixture, but it also decreases the $\mathrm{CO}_{2}$ capturing ability of the mixture. Indeed, the $[\mathrm{bmim}]\left[\mathrm{BF}_{4}\right] \mathrm{CO}_{2}$ capture performance is significantly inferior to aqueous amines. An interplay of viscosity and $\mathrm{CO}_{2}$ capture determines corrosion rate, which constitutes an important measure of the mixture efficacy.

It was not possible to identify differences between the scale morphologies formed on the surface of the steel specimens immersed in the $\mathrm{MO}$ and $\mathrm{MO}+[\mathrm{bmim}]\left[\mathrm{BF}_{4}\right]$ solutions (Figure 3). Furthermore, IL addition leads to formation of very thin and denser scales, as compared with $\mathrm{M} 0$ solution (Figure $3 \mathrm{~b}$ ). The scales are composed mainly by $\mathrm{FeCO}_{3}$ (according to EDS, Figure S2).

Polarization curves (Figure 4) were obtained using precorroded samples in the M0 solution. Five polarization curves of the precorroded steel specimens in the M0 solution

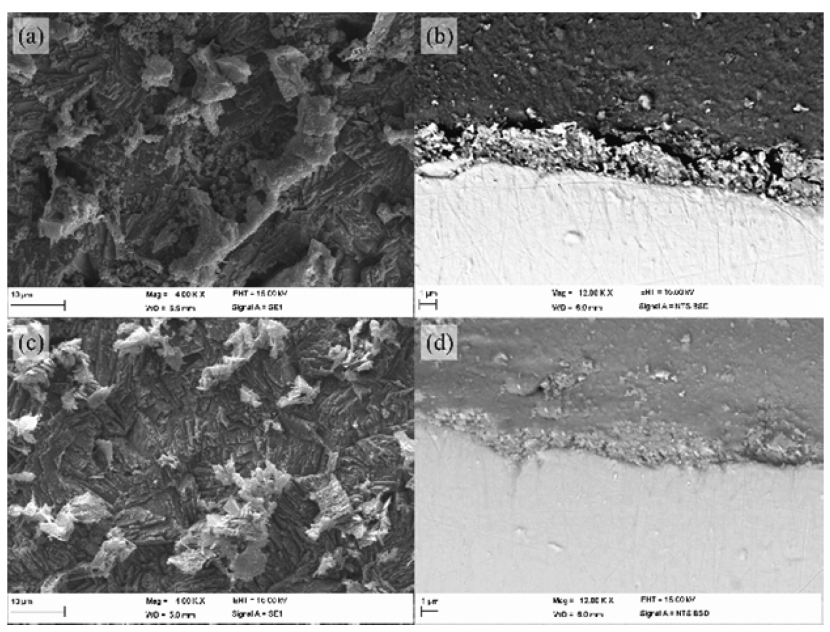

Figure 3. SEM images of the corrosion product scales formed on steel in M0 $(\mathrm{a}-\mathrm{b})$ and MIL50 $(\mathrm{c}-\mathrm{d})$, after $168 \mathrm{~h}$ of exposure at $2.7 \mathrm{MPa}$ and $318.15 \mathrm{~K}$ : $(\mathrm{a}-\mathrm{c})$ : top view; $(\mathrm{b}-\mathrm{d})$ cross-sectional view.

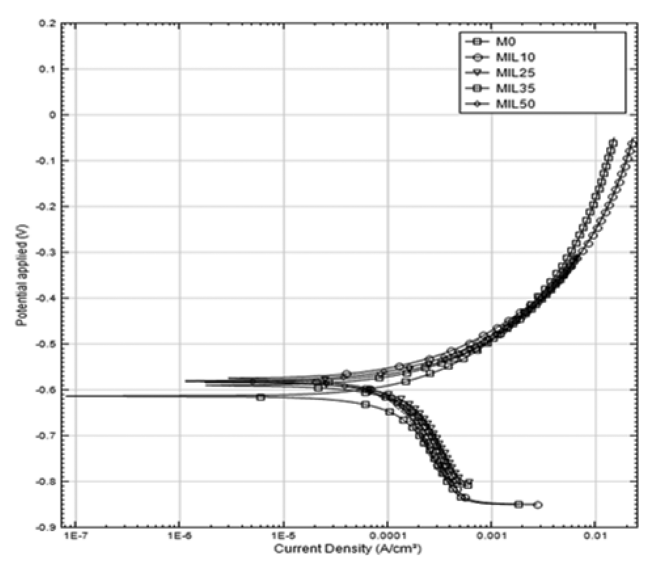

Figure 4. Polarization curves for the precorroded carbon steel in the M0 solution: with and without $[\mathrm{bmim}]\left[\mathrm{BF}_{4}\right]$, at different concentrations, after $168 \mathrm{~h}$ of exposure at $2.7 \mathrm{MPa}$ and $318.15 \mathrm{~K}$. See legend for designation of the systems.

with and without $[\mathrm{bmim}]\left[\mathrm{BF}_{4}\right]$ exhibit a similar behavior, irrespective of IL presence and concentration. One concludes that corrosion follows the same mechanism in all cases. The corrosion potential in MEA without $[\mathrm{bmim}]\left[\mathrm{BF}_{4}\right]$ is -613.4 $\mathrm{mV}$. Upon $[\mathrm{bmim}]\left[\mathrm{BF}_{4}\right]$ addition, the corrosion potential slightly shifts in the positive direction (Table S1). Current densities follow the same trend in all polarization curves. These results indicate that the addition of $[\mathrm{bmim}]\left[\mathrm{BF}_{4}\right]$ into $\mathrm{M} 0$ reduces not only corrosion rates (Figure 2) but also fosters formation of protective scales. These scales act as a diffusion barrier for $\mathrm{CO}_{2}$, therefore hindering corrosion.

In the case of the MDIL10 mixture, a corrosion decrease is observed (Figure 2). When the IL concentration exceeds $10 \%$, the corrosion rate of the steel specimen increases until the IL concentration of $35 \%$ is reached. Nearly no increase is observed at higher IL concentrations. Therefore, an ideal IL concentration is $10 \mathrm{w} / \mathrm{w} \%$. The corrosion product scales are composed mainly by $\mathrm{FeCO}_{3}$; see EDS spectrum (Figure S3). The IL concentration increase leads to larger iron carbonate crystals and to a less superficial uniformity of scales (Figure 5).

The polarization curves of the corrosion product scales formed on the steel surface after the precorroded experiments in the MD0 solution are shown in Figure 6. The corrosion of 


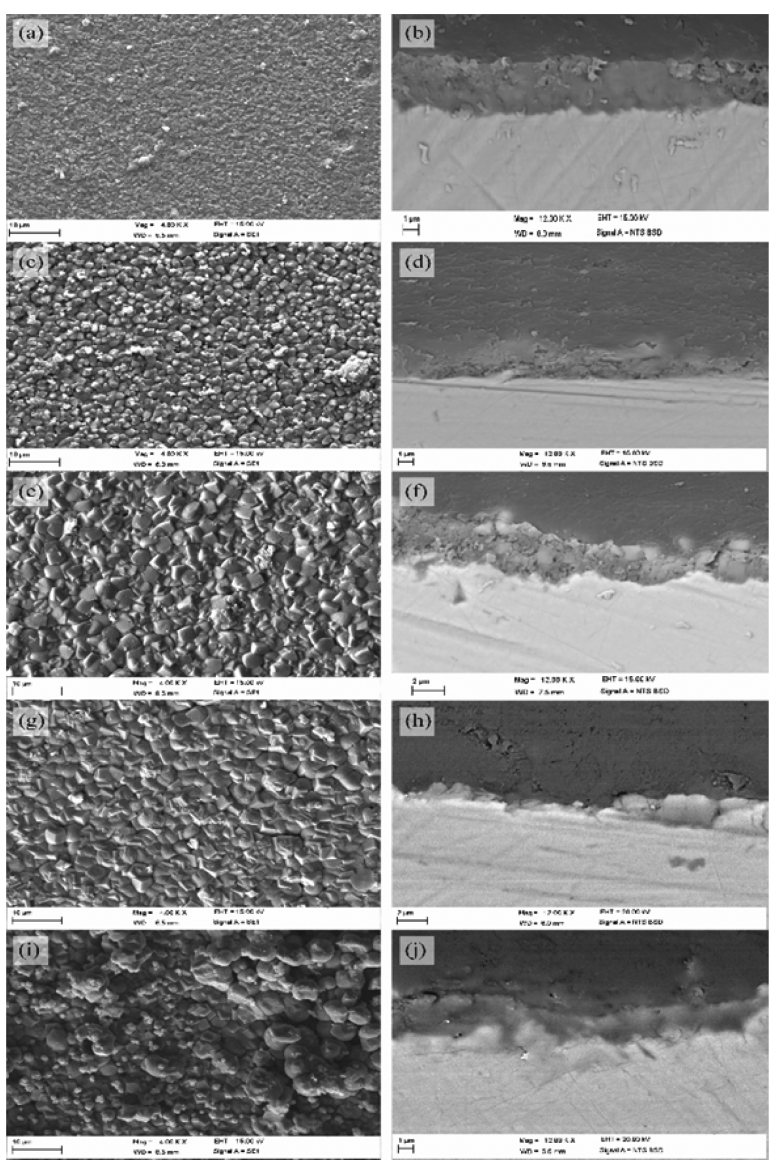

Figure 5. SEM images of the corrosion product scales formed on the steel surface in the $\mathrm{MD0}$ and $\mathrm{MD0}-[\mathrm{bmim}]\left[\mathrm{BF}_{4}\right]$ mixtures: at different concentrations, at $2.7 \mathrm{MPa}$ and $318.15 \mathrm{~K}$, after $168 \mathrm{~h}$ of exposure: (a-b) MD0, (c-d) MDIL10, (e-f) MDIL25, (g-h) MDIL35, (i-j) MDIL50. (a,c,e,g,i): top view; and $(b, d, f, h, j):$ crosssectional view.

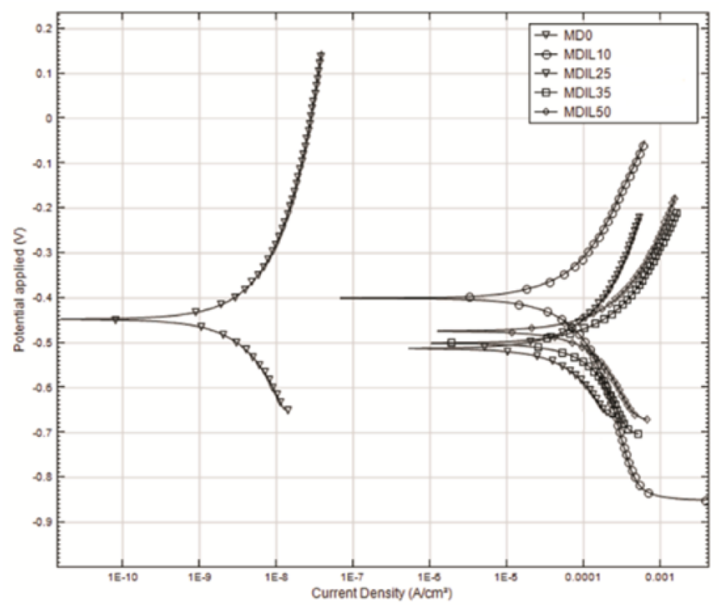

Figure 6. Polarization curves for the precorroded carbon steel in the $\mathrm{MD0}$ solution at different of $[\mathrm{bmim}]\left[\mathrm{BF}_{4}\right]$ at $2.7 \mathrm{MPa}$ and $318.15 \mathrm{~K}$, after $168 \mathrm{~h}$ of exposure: (a) MD0; (b) MDIL10; (c) MDIL25; (d) MDIL35; (e) MDIL50.

the carbon precorroded steel specimen in the MD10 system is smallest. The current densities are higher upon IL addition (Table S2). This result is in accordance with the corrosion rates determined by weight loss (Figure 2) and with the nonregular scales structure, which permits a simple oxidant access (Figure 5). The MDEA containing solutions foster formation of an ultrathin IL film on the steel specimen surface when the IL concentration is $10 \%$. However, when the $\mathrm{IL}$ concentration exceeds $10 \%$, the IL film formation is less pronounced. Otherwise, formation of an ultrathin IL film still occurs, nonetheless, formation of the $\mathrm{FeCO}_{3}$ crystals size and scales porosity are the major factors determining corrosion at high IL concentrations.

3.2. $\mathrm{CO}_{2}$ Absorption. The $\mathrm{CO}_{2}$ solubility (Figure 7) in the test solutions (MDIL10, MIL10, MIL25, MIL35, MIL50), which reduce the corrosion rate, was determined at a range of pressures.

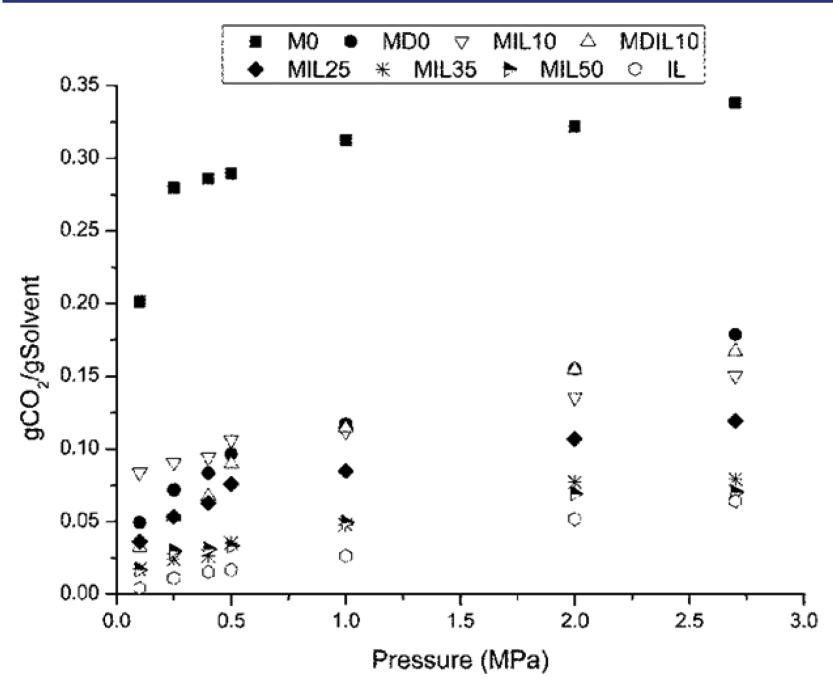

Figure 7. Carbon dioxide absorption in the test solutions at $318.15 \mathrm{~K}$

The solubility of $\mathrm{CO}_{2}$ in $\mathrm{MO}$ is the highest, whereas the solubility of $\mathrm{CO}_{2}$ in $[\mathrm{bmim}]\left[\mathrm{BF}_{4}\right]$ is lowest being in agreement with literature. ${ }^{16}$ The $\mathrm{CO}_{2}$ dissolution in ILs is a physical absorption. ${ }^{16}$ Absorption increases upon increasing $\mathrm{CO}_{2}$ partial pressure. The addition of $10 \%[\mathrm{bmim}]\left[\mathrm{BF}_{4}\right]$, see the MDIL10 system, does not result in a significantly decreased $\mathrm{CO}_{2}$ absorption. The corresponding reduction of the corrosion rate is ca. $25 \%$. In the case of M0, the addition of $25 \%, 35 \%$, and $50 \%[\mathrm{bmim}]\left[\mathrm{BF}_{4}\right]$ leads to intermediate $\mathrm{CO}_{2}$ absorption: smaller than $\mathrm{MDO}$ and higher than pure $[\mathrm{bmim}]\left[\mathrm{BF}_{4}\right]$. The corresponding reduction of the corrosion rate is ca. $72 \%$. The above results are encouraging providing a range of the ILamine compositions, which are applicable to the $\mathrm{CO}_{2}$ capture. They allow tuning $\mathrm{CO}_{2}$ absorption capacity, viscosity, and vapor pressure of the mixtures.

3.3. Numerical Simulations. Table 3 provides thermodynamic potentials for the $\mathrm{CO}_{2}$ capture via a few pathways. An ideal gas behavior of all reactants and products was assumed. We compared energetics of physical and chemical $\mathrm{CO}_{2}$ sorption, which both contribute to the observed macroscopic value. Separating these contributions is insightful for finding better compositions of the working mixtures. The capture of the first $\mathrm{CO}_{2}$ molecule per amine molecule is slightly energetically favorable. The reactions are prohibited enthalpically $(\Delta H>0)$ but allowed entropically $(T \Delta S>0)$. Chemisorption is more favorable, as compared to physisorption. This conclusion agrees with a better performance of chemical solvents, e.g., amines, and poorer performance of physical solvents, e.g., imidazolium-based ILs. This pathway of 
Table 3. Thermodynamics of Certain $\mathrm{CO}_{2}$ Capture Reactions Involving Amines ${ }^{a}$

\begin{tabular}{|c|c|c|c|c|}
\hline type of $\mathrm{CO}_{2}$ capture & $\begin{array}{c}\Delta G \\
\left.(\mathrm{~kJ} \mathrm{~mol})^{-1}\right)\end{array}$ & $\begin{array}{c}\Delta H \\
\left(\mathrm{~kJ} \mathrm{~mol}^{-1}\right)\end{array}$ & $\begin{array}{c}-T \Delta S, \\
\left(\mathrm{~kJ} \mathrm{~mol}{ }^{-1}\right)\end{array}$ & $\begin{array}{c}\Delta S \\
\left(\mathrm{~J} \mathrm{~mol}^{-1} \mathrm{~K}^{-1}\right)\end{array}$ \\
\hline $\begin{array}{l}\text { chemisorption: } \\
\text { NHRCOOH } \leftrightarrow \\
\text { MEA }+\mathrm{CO}_{2}\end{array}$ & -41.0 & +2.6 & -43.6 & +146 \\
\hline $\begin{array}{l}\text { physisorption: } \mathrm{MEA}+ \\
\mathrm{CO}_{2}\end{array}$ & -10.5 & +20.0 & -30.5 & +102 \\
\hline $\begin{array}{l}\text { chemisorption: } \leftrightarrow \\
\mathrm{MDEAH}^{+}+ \\
{\left[\mathrm{HCO}_{3}\right]^{-} \leftrightarrow} \\
\mathrm{MDEA}+\mathrm{H}_{2} \mathrm{O}+ \\
\mathrm{CO}_{2}\end{array}$ & -21.2 & +81.6 & -102 & +344 \\
\hline $\begin{array}{l}\text { physisorption: MDEA } \\
\quad+\mathrm{CO}_{2}\end{array}$ & -18.3 & +11.2 & -29.5 & +99 \\
\hline$[\mathrm{NRCOO}]^{-}+\mathrm{CO}_{2}$ & +5.5 & -57.3 & +62.8 & -211 \\
\hline $\mathrm{NHRCOOH}+\mathrm{CO}_{2}$ & +11.6 & +40.2 & -28.6 & +96 \\
\hline
\end{tabular}

${ }^{a} \mathrm{R} \equiv{ }^{\prime \prime}-\mathrm{C}_{2} \mathrm{H}_{4} \mathrm{OH}$ ". The gas-phase approximation was used in the calculations. The methodology of the computations is described in Section 2.5. Compare energetics of physical and chemical adsorption contributions upon $\mathrm{CO}_{2}$ capture. See Figure 1 for selected optimized geometries of molecular complexes and single molecules. The results are in general agreement with the available literature data. ${ }^{43,45}$.

the $\mathrm{CO}_{2}$ capture prevails. Note that chemisorption by a primary amine, MEA, and by tertiary amine, MDEA, follows different mechanisms. Carbamates, $[\mathrm{X}]^{+}[\mathrm{RHN}-\mathrm{COO}]^{-}$, are formed out of $\mathrm{RNH}_{2}$. In turn, carbamates of tertiary amines, $\left[\mathrm{R}_{1} \mathrm{R}_{2} \mathrm{R}_{3} \mathrm{~N}-\right.$ $\mathrm{COO}^{-}$, are less stable. This is in line with the experimental results (Figure 7): MEA performs better than MDEA. These compounds immediately produce bicarbonate anions. The simplified reaction scheme can be written as follows: MDEA + $\mathrm{CO}_{2}+\mathrm{H}_{2} \mathrm{O} \leftrightarrow \mathrm{H}^{+} \mathrm{MDEA}+\left[\mathrm{HCO}_{3}\right]$. All discussed reactions are reversible, with relatively small equilibrium constants. In the gas-phase approximation, the latter can be assessed as $\mathrm{K}_{\mathrm{eq}}=\exp (-\Delta G / R T)$; see $\Delta G$ in Table 3. Our computational thermodynamic potentials are in concordance with the presented experimental data for gas capture and literature results. ${ }^{4,45}$ Indeed, MDEA absorbs larger quantities of $\mathrm{CO}_{2}$ (Figure 7). We also considered capture of the second $\mathrm{CO}_{2}$ molecule per amine molecule, since the carboxyl group of the carbamate anion may be expected to exhibit certain affinity for $\mathrm{H}_{2} \mathrm{CO}_{3}$ and hydrated $\mathrm{CO}_{2}$. The calculated free energies, nevertheless, are very small suggesting limited stability of the products of such binding. [NRCOO $]^{-}$corresponds to the carbamate anion in the ammonium salt. $\mathrm{NHRCOOH}$ is a protonated anion, carbamic acid.

The applied experimental methods do not provide information about particular atom-atom interactions, binding events, and microscopic structure of mixtures. These missing data can be retrieved from numerical simulations at a reasonable cost. Thermal effect and all intra- and intermolecular interactions were accounted for by the PM7-MD simulations, which also allow to observe gas capture and in real time. Pair correlations function (PCF, Figures 8-9) constitutes a straightforward descriptor of the preferential coordination sites in the simulated four-component (amine, water, ionic liquids, carbon dioxide) systems. The systems (Table 2) are hydrophilic in nature, possessing numerous peculiar interactions. Distribution of these interactions in space ultimately determines homogeneity of the systems and their gas capture behavior at given temperature and pressure.

Figure 8 analyzes interactions that determine $\mathrm{CO}_{2}$ capture by amines, through chemisorption and physisorption. Different
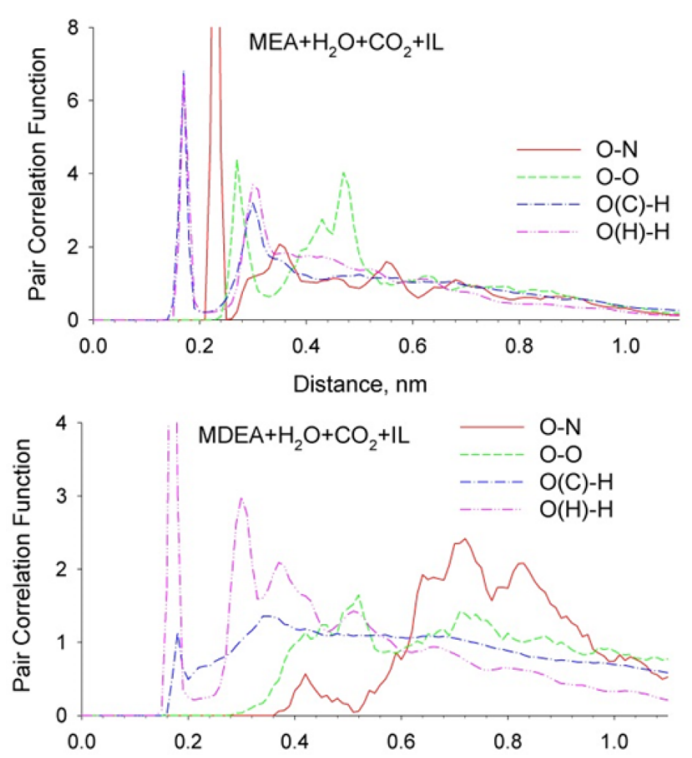

Figure 8. Pair correlation functions characterizing $\mathrm{CO}_{2}$ capture: MEA (top), MDEA (bottom). "O" is oxygen atom of $\mathrm{CO}_{2}$; "N" is the nitrogen atom of amino group; "O $(\mathrm{H})$ " is the oxygen atom of the hydroxyl group (ethanol moiety); $\mathrm{O}(\mathrm{C})$ is the oxygen atom of the carboxyl group; " $\mathrm{H}$ " is the hydrogen atom of water. See the legend for PCF designation. We provide PCFs for systems 4 (MEA) and 8 (MDEA), whereas PCFs in systems 1-3 and 5-7 qualitatively reproduce the same observations. The most probable molecular conformations are given in Figure S4.

kinds of $\mathrm{CO}_{2}$ sorption can be distinguished by the positions of the PCF peaks. Since chemisorption involves the formation of covalent bonds, the corresponding distances must be smaller than in the case of physisorption, which is driven by weaker interatomic forces. Strong hydrogen bonds are observed in all systems between hydrogen atoms of water and oxygen atoms of amines (hydroxyl group). This reflects a good mutual miscibility of amines and water. The nitrogen-oxygen distance (another high noncovalent maximum) is unusually small, 0.23 $\mathrm{nm}$, whereas the sum of the corresponding van der Waals radii exceeds $0.30 \mathrm{~nm}$. This observation indicates chemical adsorption of $\mathrm{CO}_{2}$ by $\mathrm{NH}_{2}-\mathrm{C}_{2} \mathrm{H}_{4}-\mathrm{OH}$ to form the carbonnitrogen bond ( $1.5 \AA$ long) giving rise to the $-\mathrm{OOC}-\mathrm{NH}_{2}-$ fragment. This peak is absent in the case of MDEA, since the carbamate of MDEA readily decomposes. Thus, the nitrogen atom (initially belonging to the tertiary amine) and oxygen atom (initially belonging to $\mathrm{CO}_{2}$ ) appear spatially separated.

Figure 9 analyzes interactions that determine $\mathrm{CO}_{2}$ capture by $[\mathrm{bmim}]\left[\mathrm{BF}_{4}\right]$. A hydrogen bond between the oxygen atom of $\mathrm{CO}_{2}$ and the hydrogen atom of the imidazole ring contributes to gas storage capability. It is an important finding that the gas molecules bind the cation even in the presence of amines. In addition to modulating viscosity of the mixture and protecting steel surface, $[\mathrm{bmim}]\left[\mathrm{BF}_{4}\right]$ participates in the physical adsorption of certain amount of $\mathrm{CO}_{2}$. The anion- $\mathrm{CO}_{2}$ coordination is also pronounced. In turn, the correlation between the nitrogen atoms of the imidazole ring and $\mathrm{CO}_{2}$ is fairly weak. Compare heights of peaks for chemical and physical adsorption. Chemical absorption provides a more stable product, being in agreement with our thermodynamic calculations and the $\mathrm{CO}_{2}$ capture results.

To recapitulate, the performance of MEA is better, as compared to MDEA, being in line with the results. Both amine 

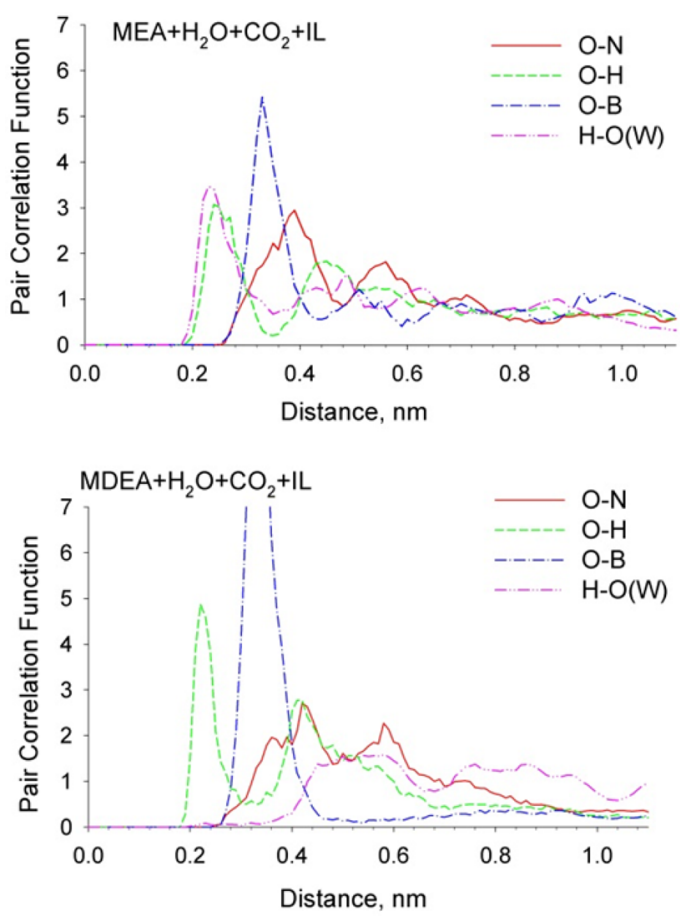

Figure 9. Pair correlation functions characterizing solvation of the imidazole ring by water and water-dissolved $\mathrm{CO}_{2}$ in MEA (top) and MDEA (bottom). "O" is the oxygen atom of $\mathrm{CO}_{2}$; " $\mathrm{N}$ " is the nitrogen atom of the imidazole ring; " $\mathrm{H}$ " is the intrinsically acidic hydrogen atom of the imidazole ring; " $\mathrm{B}$ " is the boron atom of the tetrafluoroborate anion; $\mathrm{O}(\mathrm{W})$ is the oxygen atom of water. See the legend for PCF designation. We provide PCFs for systems 4 and 8 , whereas PCFs in systems 2-3 and 6-7 qualitatively reproduce the same observations. The most probable molecular conformations are given in Figure S4.

molecules and the $\mathrm{IL}$ ions contribute to the observed $\mathrm{CO}_{2}$ storage. The performance of $[\mathrm{bmim}]\left[\mathrm{BF}_{4}\right]$ is expectedly poorer, as compared to amines. This is due to its higher molar mass (adsorption is given as gram of gas per gram of solution) and physical adsorption, which is weaker than chemisorption. Joint usage of amines and $[\mathrm{bmim}]\left[\mathrm{BF}_{4}\right]$ is interesting due to modification of the desorption rate and desorption energy cost.

\section{CONCLUSIONS}

$\mathrm{CO}_{2}$ is a primary reagent causing corrosion in these systems. The better it is bound, the smaller corrosion effects are observed. Addition of $[\mathrm{bmim}]\left[\mathrm{BF}_{4}\right]$ in MEA and MDEA provides protection against the $\mathrm{CO}_{2}$ acidic action. A range of the $\mathrm{IL}$-amines mixtures can be used for the $\mathrm{CO}_{2}$ absorption process allowing to tune desired viscosity and vapor pressure and achieve an energy penalty reduction in the desorption process. The reported experimental and theoretical results are in concordance and constitute a mutual supplement providing an evidence that $[\mathrm{bmim}]\left[\mathrm{BF}_{4}\right]$ participates in the gas capture, even though the amount of amine molecules is enough to capture all $\mathrm{CO}_{2}$ molecules. Thus, the reaction equilibrium is modified upon IL addition. The physical chemical properties of the mixed adsorbent change as a function of its content. Our present results inspire construction of more advanced $\mathrm{CO}_{2}$ capture setups.

The solution/mixture satisfying all requirements does not yet exist, and the research efforts in this direction are necessary. Our new encouraging results regarding joint usage of the imidazolium ILs and aqueous amine solutions allow to modify the $\mathrm{CO}_{2}$ capture process. Selected mixtures, based on MEA and MDEA, were investigated using versatile physical methods. Since all methods provide the results, which are in concordance with one another, the results are correct and trustworthy. Furthermore, a unique methodology combining experimental and theoretical methods, which efficiently supplement each other, is published for the first time. The computer simulations of many-component systems bears numerous technical problems. These problems come from inability of the simplified and computationally efficient methods to account for quantum effects, whereas physically accurate and rigorous ( $a b$ initio) methods are prohibitively expensive due to the iterative procedures in their core. Ab initio methods are applied to small systems (less than 100 atoms) and small times (ca. 10 ps), but the mixtures require times as larger simulations to be represented realistically. The PM7-MD simulations employed in the present work offer a competitive balance between the rigorous description and the system size.

It may be an interesting future endeavor to directly investigate the viscosity-corrosion correlation by taking a few ILs without the $\mathrm{CO}_{2}$ capture potential and with different viscosity. Such experiments would allow to separate the effect from the $\mathrm{CO}_{2}$ fixation from the effect of the viscous environment.

\section{ASSOCIATED CONTENT}

\section{S Supporting Information}

The Supporting Information is available free of charge on the ACS Publications website at DOI: 10.1021/acs.jced.5b00996.

(1) Experimental setup and disposition of carbon steel specimens for the corrosion tests; (2) EDS spectra of the corrosion product scales; (3) summary of the electrochemical results from scales; (4) most probable pathways of $\mathrm{CO}_{2}$ capture by aqueous amines (MEA and MDEA) solutions and $[\mathrm{bmim}]\left[\mathrm{BF}_{4}\right](\mathrm{PDF})$

\section{AUTHOR INFORMATION}

\section{Corresponding Author}

*E-mail for correspondence: vvchaban@gmail.com; tel.: +55 12 3309-9573; fax: +55 12 3921-8857.

\section{Funding}

Sandra Einloft and Rosane A. Ligabue thank CNPq for research scholarships. Franciele L. Bernard thanks Hewlett-Packard Brasil Ltda for a scholarship. V.V.C. got some support from CAPES.

\section{Notes}

The authors declare no competing financial interest.

\section{REFERENCES}

(1) Ketzer, J. M.; Iglesias, R. S.; Einloft, S.; Chen, W.-Y.; Seiner, J.; Suzuki, T.; Lackner, M., Eds. Handbook of Climate Change Mitigation; Springer Science+Business Media, Inc.: New York, 2012.

(2) Rivera-Tinoco, R; Bouallou, C. Comparison of Absorption Rates and Absorption Capacity of Ammonia Solvents with MEA and MDEA Aqueous Blends for CO2 Capture. J. Cleaner Prod. 2010, 18, 875-880.

(3) Kittel, J.; Fleury, E.; Vuillemin, B.; Gonzalez, S.; Ropital, F.; Oltra, R. Corrosion in Alkanolamine Used for Acid Gas Removal: From Natural Gas Processing to CO2 Capture. Mater. Corros. 2012, 63, 223-230.

(4) Hasib-ur-Rahman, M.; Siaj, M.; Larachi, F. CO2 Capture in Alkanolamine/Room-Temperature Ionic Liquid Emulsions: A Viable 
Approach with Carbamate Crystallization and Curbed Corrosion Behavior. Int. J. Greenhouse Gas Control 2012, 6, 246-252.

(5) Kenarsari, S. D.; Yang, D.; Jiang, G.; Zhang, S.; Wang, J.; Russell, A. G.; Wei, Q.; Fan, M. Review of Recent Advances in Carbon Dioxide Separation and Capture. RSC Adv. 2013, 3, 22739-22773.

(6) Iliuta, I.; Hasib-ur-Rahman, M.; Larachi, F. CO2 Absorption in Diethanolamine/Ionic Liquid Emulsions - Chemical Kinetics and Mass Transfer Study. Chem. Eng. J. 2014, 240, 16-23.

(7) Ali, B.; Si Ali, B.; Yusoff, R.; Aroua, M. K. Carbon Steel Corrosion Behaviors in Carbonated Aqueous Mixtures of Monoethanolamine and 1-N-butyl-3-methylimidazolium Tetrafluoroborate. Int. J. Electrochem. Sci. 2012, 7, 3835-3853.

(8) Hasib-ur-Rahman, M.; Bouteldja, H.; Fongarland, P.; Siaj, M.; Larachi, F. Corrosion Behavior of Carbon Steel in Alkanolamine/ Room-Temperature Ionic Liquid Based $\mathrm{CO} 2$ Capture Systems. Ind. Eng. Chem. Res. 2012, 51, 8711-8718.

(9) Wilkes, J. S. A Short History of Ionic Liquids - from Molten Salts to Neoteric Solvents. Green Chem. 2002, 4, 73-80.

(10) Zhang, Y.; Bakshi, B. R.; Demessie, E. S. Life Cycle Assessment of an Ionic Liquid versus Molecular Solvents and Their Applications. Environ. Sci. Technol. 2008, 42, 1724-1730.

(11) Plechkova, N. V.; Seddon, K. R. Applications of Ionic Liquids in the Chemical Industry. Chem. Soc. Rev. 2008, 37, 123-150.

(12) Figueroa, J. D.; Fout, T.; Plasynski, S.; Mcilvried, H.; Srivastava, R. Advances in CO2 Capture Technology: The U.S. Department of Energy's Carbon Sequestration Program. Int. J. Greenhouse Gas Control 2008, 2, 9-20.

(13) Bermúdez, M. D.; Jiménez, A. E.; Sanes, J.; Carrión, F. J. Ionic Liquids as Advanced Lubricant Fluids. Molecules 2009, 14, 2888-2908.

(14) Koel, M. Ionic Liquids in Chemical Analysis. Crit. Rev. Anal. Chem. 2005, 35, 177-192.

(15) Freudenmann, D.; Wolf, S.; Wolff, M.; Feldmann, C. Ionic Liquids: New Perspectives for Inorganic Synthesis. Angew. Chem., Int. Ed. 2011, 50, 11050-11060.

(16) Ahmady, A.; Hashim, M. A.; Aroua, M. K. Absorption of Carbon Dioxide in the Aqueous Mixtures of Methyldiethanolamine with Three Types of Imidazolium-Based Ionic Liquids. Fluid Phase Equilib. 2011, 309, 76-82.

(17) Kumar, S.; Cho, J. H.; Moon, I. Ionic Liquid-Amine Blends and CO2BOLs: Prospective Solvents for Natural Gas Sweetening and CO2 Capture Technology - a Review. Int. J. Greenhouse Gas Control 2014, 20, 87-116.

(18) Yang, J.; Yu, X.; Yan, J.; Tu, S. CO2 Capture Using Amine Solution Mixed with Ionic Liquid. Ind. Eng. Chem. Res. 2014, 53, 2790-2799.

(19) Baj, S.; Siewniak, A.; Chrobok, A.; Krawczyk, T.; Sobolewski, A. Monoethanolamine and Ionic Liquid Aqueous Solutions as Effective Systems for CO2 Capture. J. Chem. Technol. Biotechnol. 2013, 88, $1220-1227$.

(20) Gao, J.; Cao, L.; Dong, H.; Zhang, X.; Zhang, S. Ionic Liquids Tailored Amine Aqueous Solution for Pre-Combustion CO2 Capture: Role of Imidazolium-Based Ionic Liquids. Appl. Energy 2015, 154, 771-780.

(21) Huang, Y.; Zhang, X.; Zhang, X.; Dong, H.; Zhang, S. Thermodynamic Modeling and Assessment of Ionic Liquid-Based CO2 Capture Processes. Ind. Eng. Chem. Res. 2014, 53, 11805-11817.

(22) Ahmady, A.; Hashim, M. A.; Aroua, M. Kinetics of Carbon Dioxide Absorption into Aqueous MDEA+[bmim][BF4] Solutions from 303 to 333 K. Chem. Eng. J. 2012, 200-202, 317-328.

(23) Hasib-ur-Rahman, M.; Larachi, F. Prospects of Using RoomTemperature Ionic Liquids as Corrosion Inhibitors in Aqueous Ethanolamine-Based $\mathrm{CO} 2$ Capture Solvents. Ind. Eng. Chem. Res. 2013, 52, 17682-17685.

(24) Shojaeian, A.; Haghtalab, A. Solubility and Density of Carbon Dioxide in Different Aqueous Alkanolamine Solutions Blended with 1Butyl-3-methylimidazolium Acetate Ionic Liquid at High Pressure. J. Mol. Liq. 2013, 187, 218-225.
(25) Hamah-Ali, B.; Si Ali, B.; Yusoff, R.; Aroua, M. K. Corrosion of Carbon Steel in Aqueous Carbonated Solution of MEA/[bmim][DCA]. Int. J. Electrochem. Sci. 2011, 6, 181-198.

(26) Welton, T. Room Temperature Ionic Liquids - Solvents for Synthesis and Catalysis. Chem. Rev. 1999, 99, 2071-2083.

(27) Wasserscheid, P.; Welton, T. Ionic Liquids in Synthesis; WileyVCH Verlags GmbH \& Co.: Weinheim, 2008.

(28) Paolinelli, L. D.; Pérez, T.; Simison, S. N. The Effect of PreCorrosion and Steel Microstructure on Inhibitor Performance in CO2 Corrosion. Corros. Sci. 2008, 50, 2456-2464.

(29) Zhang, G. A.; Cheng, Y. F. Localized Corrosion of Carbon Steel in a CO2-Saturated Oilfield Formation Water. Electrochim. Acta 2011, $56,1676-1685$.

(30) ASTM G1-03 Standard Practice for Preparing, Cleaning and Evaluating Corrosion Tests Speciments. West Conshohocken, PA, USA, 2011.

(31) ASTM G31-72 Standard Practice Laboratory Immersion Corrosion Testing of Metals. West Conshohocken, PA, USA, 2004.

(32) Blasig, A. B.; Tang, J.; Hu, X.; Shen, Y.; Radosz, M. Magnetic Suspension Balance Study of Carbon Dioxide Solubility in Ammonium-Based Polymerized Ionic Liquids: Poly(p-vinylbenzyltrimethyl Ammonium Tetrafluoroborate) and Poly([2(methacryloyloxy)ethyl] Trimethyl Ammonium Tetrafluoroborate). Fluid Phase Equilib. 2007, 256, 75-80.

(33) Dreisbach, F.; Losch, H. W. Magnetic Suspension Balance for Simultaneous Measurement of a Sample and the Density of the Measuring Fluid. J. Therm. Anal. Calorim. 2000, 62, 515-521.

(34) Chaban, V. V.; Prezhdo, O. V. Are Fluorination and Chlorination of Morpholinium-Based Ionic Liquids Favorable? J. Phys. Chem. B 2015, 119, 9920-9924.

(35) Cizek, J. Origins of Coupled Cluster Technique for Atoms and Molecules. Theor. Chim. Acta 1991, 80, 91-94.

(36) Andreeva, N. A.; Chaban, V. V. Global Minimum Search via Annealing: Nanoscale Gold Clusters. Chem. Phys. Lett. 2015, 622, 7579.

(37) Chaban, V. V. Competitive Solvation of (Bis) (trifluoromethanesulfonyl)imide Anion by Acetonitrile and Water. Chem. Phys. Lett. 2014, 613, 90-94.

(38) Chaban, V. V. Competitive Solvation of the Imidazolium Cation by Water and Methanol. Chem. Phys. Lett. 2015, 623, 76-81.

(39) Chaban, V. V. The Thiocyanate Anion is a Primary Driver of Carbon Dioxide Capture by Ionic Liquids. Chem. Phys. Lett. 2015, 618, 89-93.

(40) Stewart, J. J. Optimization of Parameters for Semiempirical Methods VI: More Modifications to the NDDO Approximations and Re-Optimization of Parameters. J. Mol. Model. 2013, 19, 1-32.

(41) Andersen, H. C. Molecular Dynamics Simulations at Constant Pressure and/or Temperature. J. Chem. Phys. 1980, 72, 2384-2393.

(42) Zhou, X.; Yang, H.; Wang, F. BMIMBF4 Ionic Liquids as Effective Inhibitor for Carbon Steel in Alkaline Chloride Solution. Electrochim. Acta 2011, 56, 4268-4275.

(43) Chen, S. M.; Chen, S. Y.; Zhang, Y. C.; Chai, H.; Qin, L.; Gong, $\mathrm{Y}$. T. An Investigation of the Role of N-methyl-diethanolamine in Non-Aqueous Solution for CO2 Capture Process Using 13C NMR Spectroscopy. Int. J. Greenhouse Gas Control 2015, 39, 166-173.

(44) Yu, C. H.; Huang, C. H.; Tan, C. S. A Review of CO2 Capture by Absorption and Adsorption. Aerosol Air Qual. Res. 2012, 12, 745769.

(45) Zhang, Y.; Chen, C. C. Thermodynamic Modeling for CO2 Absorption in Aqueous MDEA Solution with Electrolyte NRTL Model. Ind. Eng. Chem. Res. 2011, 50, 163-175. 